\title{
PRUNE BELLY SYNDROME: A RARE CASE REPORT
}

\author{
MD. ABDUL AWAL ${ }^{1}$, SHAHARA HAQUE ${ }^{2}$, MST. NAZMUN NAHAR ${ }^{2}$, HUSNE ARA ${ }^{2}$, FARHANA KAMAL ${ }^{2}$
}

${ }^{1}$ Dept. of Urology, Sher-e-Bangla Medial College, Barisal, ${ }^{2}$ Department of Radiology, DMC, Dhaka

\begin{abstract}
:
Prune belly Syndrome (PBS), a rare congenital anomaly of uncertain aetiologies has been seldom reported among Bangladeshis. Prune belly syndrome is a birth defect that involve three main problems like poor development of the abdominal musclescausing the skin of the belly area to wrinkle like a prune, undescended testicles and urinary tract problems. We report a case of 15 days old term male neonate with PBS. The baby named Shumon was admitted in Dhaka Medical College Hospital with complaint of lax abdominal wall, absence of both testes since birth. He was born by NVD and consulted with a local doctor who commented that the baby was not normal and referred to Dhaka Medical College Hospital for better management. On physical examination the baby weighted $2.7 \mathrm{Kg}$ and full length was $40 \mathrm{~cm}$. He was mildly pale, his respiratory rate was 32 cycles per minute with normal breath sounds. Heart rate was 134 beats per minute. His abdomen was flabby with a wrinkled appearance and there were visible peristalses with palpable kidneys \& bilateral undescended testes. His B.P was within normal range and cardiac examination was normal clinically and echocardiographically. USG of abdomen showed bilateral gross hydronephrosis with mega ureter. Micturating cystography showed grade-IV vesico-ureteric reflux bilaterally with no urethral obstruction.
\end{abstract}

Serum creatinine concertration was $80 \mu \mathrm{mol} / \mathrm{L}$, Serum Sodium was $130 \mathrm{mmol} / \mathrm{L}$ and Serum Potassium was $5.8 \mathrm{mmol} / \mathrm{L}$. The presumptive diagnosis was Prune Belly Syndrome.

Bangladesh J. Urol. 2014; 17(1): 53-58

\section{Introduction:}

In 1839 Frolich first described this as Prune belly Syndrome, also called Eagle-Barrett Syndrome, Obrinsky syndrome and triad syndrome, consists of congenital urinary tract abnormalities bilateral cryptorchidism and wrinkled anterior abnormal wall due to deficits in the musculature. A lack of abdominal muscles leads to a poor cough mechanism, which in turn, leads to increased pulmonary secretions[1]. Weak abdominal muscles lead to constipation because of inability to perform the Valsalva maneuver, which helps to push the stool out of the rectum during defecation.

It occurs in about 1 in 50,000 live births and the etiology is unknown. Approximately $96-97 \%$ of prune belly syndromes occur in boys. Only approximately $3-4 \%$ of

Correspondences: Md. Abdul Awal, Dept. of Urology, Sher-eBangla Medial College, Barisal e-mail: maawaluro@yahoo.com all PBS cases occur in case of females. Twinning is associated with prune belly syndrome, Prune belly Syndrome is more common among black Americans[3]. The mortality associated with PBS is $20 \%$. PBS is associated with trisomy 18 and 21. Patient with PBS also have an increased incidence of tetralogy of Fallot and ventriculoseptal defects[2].

\section{Case Report:}

A baby named Shumon (B/O Mrs. Lovely) was admitted in Dhaka Medical College Hospital with complaint of lax abdominal wall since birth, absence of both testes since birth. He was born by NVD and referred to Dhaka Medical College Hospital for better management.

On physical examination it was found that the patient baby is weighted $2.7 \mathrm{Kg}$ and full length of $40 \mathrm{Cm}$. He was mildly pale, his respiaratory rate was 32 cycles per minute with normal breath sounds. The heart rate was 


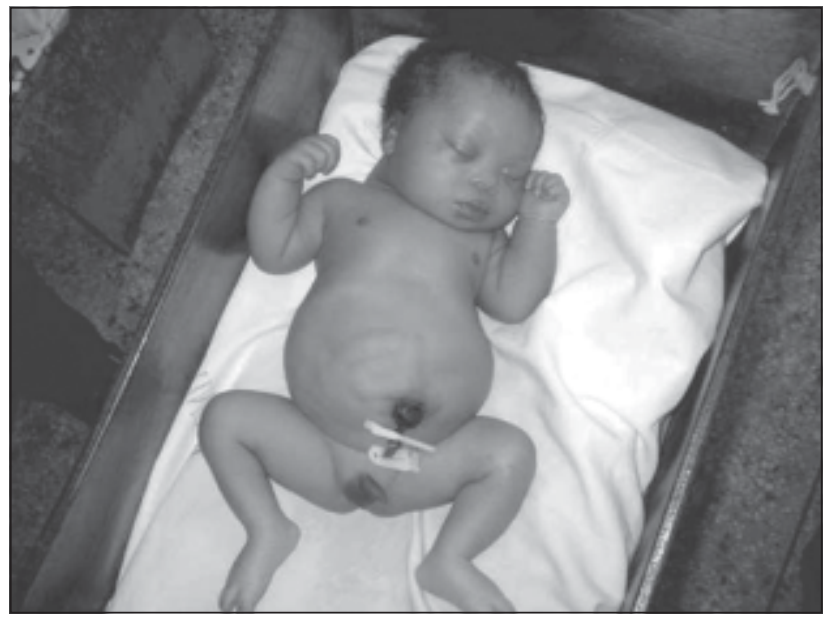

Fig.-1: Shows lax abdomen with wrinkled appearance

134 beats per minute. His abdomen was flabby with a wrinkled appearance and visible peristalses with palpable kidneys \& bilateral undescended testes. His B.P was within normal range and cardiac examination was normal. USG of abdomen showed bilateral gross hydronephrosis with mega ureter. Micturating cystography showed grade-IV vesicoureteric reflux bilaterally with no urethral obstruction.

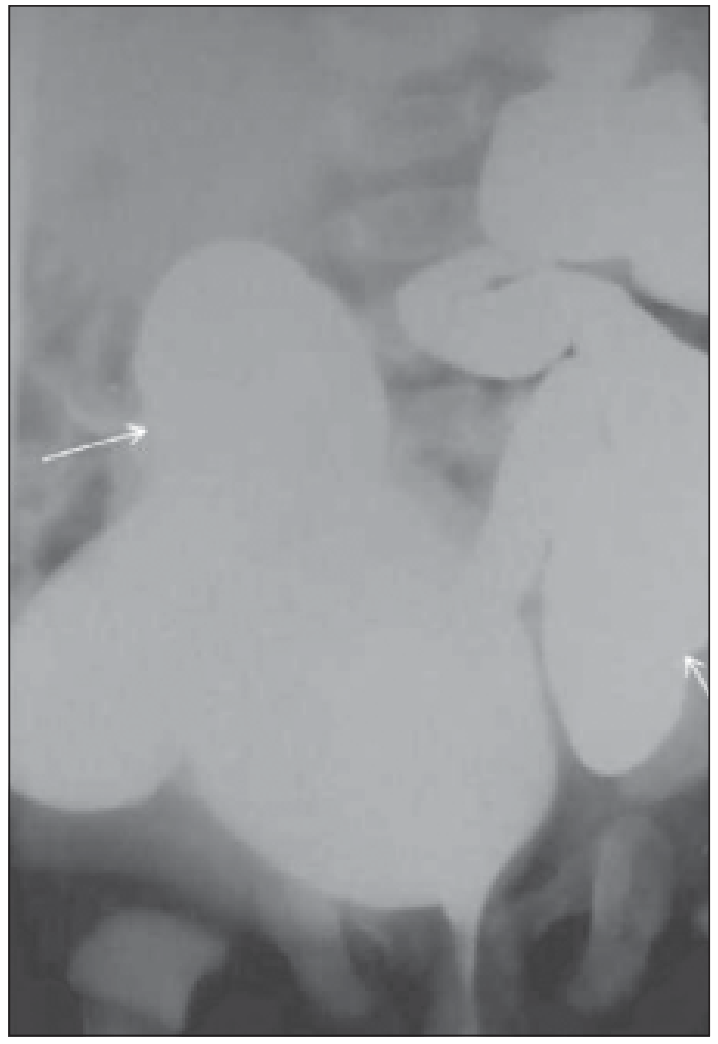

Fig.-2: Micturating cystourethrography shows grade-IV vesicoureteric reflux and megaureter.
Serum Creatinine Concertration was $80 \mathrm{~s} \_\mu \mathrm{mol} / \mathrm{L}, \mathrm{S}$. Sodium was $130 \mathrm{mmol} / \mathrm{L}$ and S. Potassium was 5.8 $\mathrm{mmol} / \mathrm{L}$. The baby was managed in hospital. Surgical reconstruction of abdominal wall was done to improve respiratory function and to improve the cosmosis. Management of undescended testis was done by laparoscopic technique as this technique reduces the mobility associated with abdominal surgery.

\section{Discussion:}

Renal hypoplasia, hydroureter, hydrodronephrosis, ureterovesical ureteropelvic junction obstruction ,Posterior urethral valve \& vesico ureteric reflux have all been associated with PBS[4]. Current theory suggests that there is a mesenchymal insult of the fetus at 6 weeks of gestation resulting in deficient abdominal muscular development[8]. A second theory suggests that the problem may be secondary to chronic intrauterine abdominal distension with subsequent pressure atrophy of abdominal muscles[5]. The prognosis of PBS is poor with still births and early infant death being common[11]. Diao et al. Reported that renal failure is the main cause of death in PBS[2].

\section{Conclusion:}

PBS occurs with variable degrees of severity. In severe cases, renal dysplasia \& oligohydramnios in utero result in pulmonary hypoplasia.

Those with little severe renal disease may survive infancy, but may have recurrent UTI \& progressive renal insufficiency.

Routine antenatal USG will help in discovering renal anomalies, which can be followed postnatally. Post natal diagnosis of PBS necessitates full radiological investigations to detect renal anomalies. Early diagnosis of this syndrome and determining its optimal treatment are very important in helping to avoid its fatal course.

Conflict of Interest : None Declared

\section{References:}

1. Bellah RD, States LJ, Duckett JW. PseudopruneBelly sybdrome: imaging findings and clinical outcome. AJR Am J Roentgenol. Dec 1996; f67(6): 1389-93

2. Diao B, Dialloy, Fall PA, Ngom G. Fall B, Ndoye AK, Fall I, Ba M, Nodoye M, Diagne BA. Prune Belly Syndrome: Epidemiologic, Clinic of therapeutic effects. prog urol 2008; 18 (7): 470474.

3. Waldbaum RS, Marshall. The prune belly syndrome: a diagnostic therapeutic plan. J Urol. May 1970; 103(5): 668-74 
4. Egli F, Stalder G. Malformation of kidney \& urinary tract in common chromosomal aberrations. I Clinical studies Humangenetic 1973; 18: 1-15.

5. Amacker Es, Grass FS, Hickey DE, Hisley JC. Brief clinical report: An associaltion of prune belly syndrome anomay with trisomy 21. AMJ Med Genet 1986; 23: 919-92

6. Monfont G Guys JM, Bocciadi A, Coquet M, Chevallier D. A novel technique for reconstruction of abdominal wall in prune belly syndrome. Urology Mar 1993; 41(3): 231-2.
7. Woodard JR, Parrot TS. Reconstruction of urinary tract in prune belly uropathy. J Urol. June 1978; 119(6): 824-8.

8. Duckett J Knutru O, Holhenfellner R. Prune belly syndrome. J urol. 1980; 3: 9.

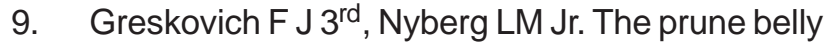
syndrome: a review of its etiology, defects, treatment and prognosis. J Urol. Oct 1988; 140(4): 707-12.

Abbreviations:

NVD : Normal vaginal delivery

PBS : Prune Belly Syndrome 